\title{
ASSESSMENT OF KNOWLEDGE, ATTITUDE, AND PRACTICE ABOUT PACKAGE INSERTS AMONG MEDICAL UNDERGRADUATE STUDENTS: A CROSS-SECTIONAL QUESTIONNAIRE-BASED STUDY
}

\author{
SNEHA PRABHA MP, SONISH S PRABHAKARAN*
}

Department of Pharmacology, Government Medical College, Thiruvananthapuram, Kerala, India. Email: spsp.pharm@gmail.com

Received: 12 December 2020, Revised and Accepted: 14 January 2021

\section{ABSTRACT}

Objective: The objective of our study was to assess knowledge, attitude, and practice regarding package inserts (PIs) among medical undergraduates of a Government Medical College in Kerala, India

Methods: A cross-sectional, questionnaire-based study was carried out on 100 medical students. It was conducted with the consent of all participants and after the approval of Institutional Review Board and Ethics Committee. Pre-validated 15 items questionnaire was used to elicit responses about knowledge, attitude, and practice with a scoring scheme of +1 for "yes"/positive response and 0 for "no/I don't know"/negative response. Data analyzed using "SPSS" and responses were expressed as mean scores and percentages.

Results: Statistical analysis (response rate 98\%) revealed that $88.2 \%$ have seen PIs but only $18.4 \%$ had the knowledge of drug acts governing the information to be provided on PIs in India. About 78.6\% agreed PIs are necessary add-on to drug information. About $62.2 \%$ opined that PIs must be in regional language along with English. About 100\% agreed that written information in PIs is difficult to read and understand. About $66.3 \%$ feel that doctors must instruct patients to read PIs thoroughly. About 71.4\% have referred PIs as a source of knowledge for Indication/Contraindication/ Adverse Effects/Drug interaction. About 95.9\% would like to refer PIs in future while prescribing as physician.

Conclusion: We conclude that participants have positive attitude toward PIs but have less knowledge as compared with developed countries. Results suggest the need for escalating knowledge and awareness among medical students about PIs which, in turn, help to minimize medication errors.

Keywords: Questionnaire, Package inserts, Knowledge.

(c) 2021 The Authors. Published by Innovare Academic Sciences Pvt Ltd. This is an open access article under the CC BY license (http://creativecommons.org/ licenses/by/4.0/) DOI: http://dx.doi.org/10.22159/ajpcr.2021v14i3.40477. Journal homepage: https://innovareacademics.in/journals/index.php/ajpcr

\section{INTRODUCTION}

Drug labeling refers to all of the printed information that accompanies a drug, including the label, the wrapping, and the package insert (PI) [1]. PI is a printed leaflet that contains information based on regulatory guidelines for the safe and effective use of a drug. It is also known as a prescription drug label or prescribing information. The information in the PI is evidence-based and is updated from time to time, as relevant preclinical and clinical data become available [2]. Regulatory requirements for drug PI or leaflets vary across nations. In India, the design and amount of information in PI are governed by the "Drugs and Cosmetics Act (1940) and Rules (1945). Section 6 of Schedule D (II) of the rules lists the headings according to which information should be provided in the PIs [3,4]. Section 6 of Schedule D (II) of the rules lists the headings according to which information should be provided in the PIs. Section 6.2" mandates that the PIs must be in "English" and must include information on indications, posology, method of administration, contraindications, special warnings and precautions, drug interactions, pregnancy and lactation, use of machinery, undesirable effects, and antidote for overdose. "Section 6.3" mandates pharmaceutical information on the list of excipients, incompatibilities, shelf life, special precaution for storage, nature, and specification of container and instruction for use and handling [4]. PIs are primarily intended for the use of registered medical practitioners or a hospital or a laboratory [4]. However, it is not mentioned clearly, whether PI are directed only at the physicians or at the patients as well [4,5]. By virtue of being amenable to strict regulations, and being readily available with the drug product, PIs can serve as reliable and accurate sources of drug information for health-care providers [6]. In developing countries like India, where the doctor-patient ratio is about 1:1700 which is much less than the recommended 1:1000 [7], PIs will give a piece of complete information about the drug in addition to the instructions given by the doctor. A good PIs also helps to decrease prescribing errors such as incorrect medication dosage, incorrect duration of treatment, and incomplete patient instructions, which range from $29 \%$ to $56 \%$ of all reported medical errors in adults [8]. PIs also serve as an important source of drug information for prescribing doctors, due to limited access to up-to-date information about newer drugs, especially in developing countries. In countries like India, where self-medication is more prevalent than in developed countries, good PI can prevent various medication errors [5,9]. In a study done in India, self-medication was found to be very common especially for conditions such as fever and headache [10]. Another study about self-medication on medical and nonmedical students in India, showed medical students follow PI as reading material than non-medical students [11]. Several studies have also shown that PIs help to bridge the information gap between healthcare providers and patient's knowledge about drugs and thus increase patient compliance [12-14]. Hence, a decision was taken to conduct a study, to evaluate the knowledge and attitude of medical students toward PI. Results of this study provide information for health-care providers and educators

\section{METHODS}

\section{Study design}

This study was a cross-sectional, questionnaire-based study carried out on 100 medical students who passed the pharmacology exam, of a Government Medical College in Kerala, India. The study was initiated after getting the Institutional Review Board and Ethics Committee Approval. The study was conducted from August 2020 to September 2020 (2 months). The participants were briefed about the study 
procedure and written informed consent was taken from all the participants. A self-administered, pre-validated 15 items questionnaire was used to elicit responses from the students about the knowledge, attitude, and practice regarding PI. PI in this study is defined as a printed leaflet that contains information based on regulatory guidelines for the safe and effective use of a drug. The questionnaire was adapted from previous studies and modifications were done in the questionnaire with reference to "Drug and Cosmetics Act (1940) and rules (1945)" [4,5]. The questionnaire was validated by piloting among postgraduate students of the department of pharmacology $(n=18)$ for content and time. The reliability assessed by Cronbach's alpha was 0.87 .

The questionnaire was distributed to the participants after explaining the nature and purpose of the study. All the students who agreed to complete the questionnaires and were willing to participate in the study were included in the study. About $1 / 2 \mathrm{~h}$ was given to the participants to fill the questionnaire. The completed questionnaires, from 100 medical students who gave consent, were then assessed for responses of the students about their knowledge and awareness regarding PI. Out of 100, 98 duly filled questionnaires were taken for statistical analysis.

\section{Scoring of PI}

The questionnaire has four domains. Other than the demographic variable, the other three domains were knowledge, attitude, and practice. There were five questions in knowledge, seven questions in attitude, and three in the practice section. For knowledge "yes" response was given a score of 1 and for "no"/ "I don't know" responses score given was 0 . For attitude, the positive response was attributed 1, and for negative response 0 . For practice was expressed as binary variables, yes/no.

\section{Statistical analysis}

The data were analyzed with the help of the SPSS 22 trial version and responses were expressed as mean \pm standard deviation and percentage. The difference in mean scores of knowledge and attitude among males and females was checked with an independent t-test. The statistical significance was fixed at a $p<0.05$ with a $95 \%$ confidence limit.

\section{RESULTS}

Out of the 100 questionnaires distributed all 98 were returned with a response rate of $98 \%$. Demographic characteristics of participants are given in Table 1.

In our study, the majority of students, $88.2 \%(\mathrm{n}=87)$ have seen PI. However, only $18.4 \%(n-=18)$ had the knowledge of drug acts governing the information to be provided on PIs in India. About 78.6\% ( $n=77)$ of students agreed that PIs are a necessary add-on to drug information. About $71.4 \%(\mathrm{n}=70)$ of students think that information given on PI are useful for the patients and $62.2 \%(n=61)$ of students had the opinion that PIs should be in regional language along with English. However, $100 \%(\mathrm{n}=98)$ of students agreed that written information in PIs are not easy to read and understand and all students opinioned that the information on PIs should be improved in our country. About $66.3 \%$ $(n=65)$ of students think that PIs should be used for all drugs and $66.3 \%$ $(n=65)$ of students feel that doctors should instruct the patients to read PIs thoroughly. About 78.6\% ( $\mathrm{n}=77)$ of students agreed that they understand the information given in PI and $71.4 \%(n=70)$ have referred to PIs as a source of knowledge for Indication/Contraindication/ Adverse Effects/Drug interaction. Out of $71.4 \%, 48.9 \%$ looked for

Table 1: Demographic characteristics of participants

\begin{tabular}{ll}
\hline Characteristics & Participants (n=98), \% \\
\hline Gender & \\
Male & $46(46.9)$ \\
Female & $52(53.1)$ \\
Age (Mean age \pm SD) (years) & \\
$\quad$ Male & $22.89 \pm 0.61$ years \\
females & $22.67 \pm 0.59$ years \\
\hline
\end{tabular}

adverse effects, $43.8 \%$ for contraindications, $42.8 \%$ for indications, $41.8 \%$ for drug interactions, $39.7 \%$ for dosage, $35.7 \%$ for precautions, $31.6 \%$ for overdosage, $27.5 \%$ for pregnancy and lactation, and $33.6 \%$ looked for other information which includes pharmacodynamics, storage information, special warnings and precautions, and shelf life. About $95.9 \%(n=94)$ said that they will refer PI in future while prescribing as a physician.

The mean knowledge score was $2.48 \pm 1.33$ (out of 5). On comparing the mean knowledge scores among males $(2.39 \pm 1.36)$ and females $(2.56 \pm .32)$, it was found that there was no statistically significant difference in the mean scores ( $\mathrm{t}=0.62, \mathrm{p}=0.54)$. The mean attitudinal score was $4.45 \pm 2.15$ (considering positive attitude as 1 and negative attitude as 0 , total score out of 7). On comparing the mean attitudinal scores among males (4.52 \pm 2.2 ) and females (4.38 $\pm .2 .12)$, it was found that there was no statistically significant difference in the mean scores $(\mathrm{t}=0.31, \mathrm{p}=0.76)$ Fig. 2 .

\section{DISCUSSION}

PIs are officially approved document that accompanies a drug. It contains all essential and accurate information about the drug and is intended for the safe and effective use of drugs $[3,15]$. The quality and quantity of information available in the PIs also help the prescribers to have up-to-date information about drugs [16]. PIs also help to minimize prescribing errors such as incorrect dosage, incorrect duration of treatment, and incomplete patient instructions [8]. In our study, the majority of students, $88.2 \%(\mathrm{n}=87)$ have seen PI. But only $18.4 \%$ $(n=18)$ had the knowledge of drug acts governing the information to be provided on PIs in India. These results are slightly higher than a similar study done by Gupta et al. [17] on postgraduate medical students which showed only $2.9 \%$ of students were aware of the drug acts governing the information to be provided on PIs. About $78.6 \%$ ( $n=77$ ) of students agreed that PIs are a necessary add on to drug information and $71.4 \%$ $(n=70)$ of students opined that information given on PI are useful for the patients, though only $66.3 \%$ were of the opinion that PIs should be used for all drugs. These results are consistent with another study of Singh et al. who assessed the degree of awareness of PIs among physicians and patients [18]. All students $(100 \%)$ agreed that the information in PIs is not easy to read and understand. Several studies reveal the need for improvement in the structure of PIs by standardizing the font size and type, line spacing, headings and subheadings presented in a standardized order, letters in white background, and good quality paper for printing $[19,20]$. In a similar study done by Kafeel et al. who assess awareness of PIs among general practitioners, pharmacists, and the general public of Karachi city, the respondents were asked about for the possible reason due to which most people dislike to read PIs and $56.6 \%$ opined because of medical terminologies, $45.7 \%$ opined because of extensive information provided, and $28.1 \%$ opined because of small font size [21]. In our study, $66.3 \%(n=65)$ of students feel that doctors should instruct the patients to read PIs thoroughly and $62.2 \%$ $(n=61)$ of students had the opinion that PIs should be in regional language along with English, which can help patients to understand the information in PI in a better way. The patients who read the PI are more likely to follow the instructions, of health-care providers and are less likely to face serious consequences of the drug [22]. These results were comparable to other studies done by Gupta et al. [17], Gupta et al. [9], and Shivkar et al. [5]. However, this percentage is much less than studies done in developed countries and countries such as Saudi Arabia and Iran where the reported percentage of patients who read PIs were found to be very high [23,24]. About $78.6 \%(n=77)$ of students agreed that they understood the information given in PI and $71.4 \%(\mathrm{n}=70)$ have proposed PIs as a source of knowledge for Indication/Contraindication/Adverse Effects/Drug interaction. In our study, adverse effects, contraindications, and indications were the most referred information on PI $(48.9 \%, 43.8 \%$, and $42.8 \%$, respectively) whereas special warnings/precautions, overdosage, and pregnancy/ lactation were the least read columns $(35.7 \%, 31.6 \%$, and $27.5 \%$, respectively). The percentages are slightly more than in a similar study 
Table 2: Questionnaire

\begin{tabular}{|c|c|c|c|}
\hline \multirow[t]{2}{*}{ Qn No } & \multirow[t]{2}{*}{ Questions } & \multicolumn{2}{|l|}{$n=98(\%)$} \\
\hline & & Yes & No \\
\hline 1 & Have you seen a package insert (PI) available with drugs? & $87(88.2 \%)$ & $11(11.2 \%)$ \\
\hline 2 & $\begin{array}{l}\text { Do you know which drug act governs the information to be } \\
\text { provided on PIs? }\end{array}$ & $18(18.4 \%)$ & $80(81.6 \%)$ \\
\hline 3 & $\begin{array}{l}\text { Are PIs also known as "prescription drug labels" } \mathrm{r} \\
\text { "prescribing information"? }\end{array}$ & $21(21.4 \%)$ & 77 (78.6\%) \\
\hline 4 & $\begin{array}{l}\text { Does the rule } 6.2 \text { mandates package inserts must be in } \\
\text { English? }\end{array}$ & 27 (27.6\%) & $71(72.4 \%)$ \\
\hline 5 & $\begin{array}{l}\text { Does Section } 6.3 \text { of the rule mandate the pharmaceutical } \\
\text { information must be included in PI? }\end{array}$ & $34(34.7 \%)$ & $64(65.3 \%)$ \\
\hline 6 & Do you think PI is a necessary add-on to drug information? & 77 (78.6\%) & $21(21.4 \%)$ \\
\hline 7 & $\begin{array}{l}\text { Do you think that the information given on PI is useful for } \\
\text { the patients? }\end{array}$ & $70(71.4 \%)$ & $28(28.6 \%)$ \\
\hline 8 & $\begin{array}{l}\text { Do you think that written information on PI is easy to read } \\
\text { and understand? }\end{array}$ & 98 (100\%) & 0 \\
\hline 9 & $\begin{array}{l}\text { Do you think PIs should be in regional language also, along } \\
\text { with English? }\end{array}$ & $61(62.2 \%)$ & $37(37.8 \%)$ \\
\hline 10 & $\begin{array}{l}\text { Do you think that information on PIs should be improved in } \\
\text { our country? }\end{array}$ & 98 (100\%) & 0 \\
\hline 11 & Do you think that PI would be used for all drugs? & $65(66.3 \%)$ & $33(33.7 \%)$ \\
\hline 12 & $\begin{array}{l}\text { Do you feel that doctors should instruct the patients to read } \\
\text { the PIs thoroughly? }\end{array}$ & $65(66.3 \%)$ & $33(33.7 \%)$ \\
\hline 13 & Do you understand package inserts? & 77 (78.6\%) & $21(21.4 \%)$ \\
\hline 14 & $\begin{array}{l}\text { Have you ever referred to PIs as a source of knowledge for } \\
\text { Indications/Contraindications/Adverse Drug Reactions/ } \\
\text { Drug Interactions? } \\
\text { The information you often looked for in package } \\
\text { insert (multiple answers possible)-See Figure } 1\end{array}$ & $70(71.4 \%)$ & $28(28.6 \%)$ \\
\hline 15 & $\begin{array}{l}\text { Will you refer package inserts in the future while prescribing } \\
\text { as a physician? }\end{array}$ & 94 (95.9\%) & $4(4.1 \%)$ \\
\hline
\end{tabular}

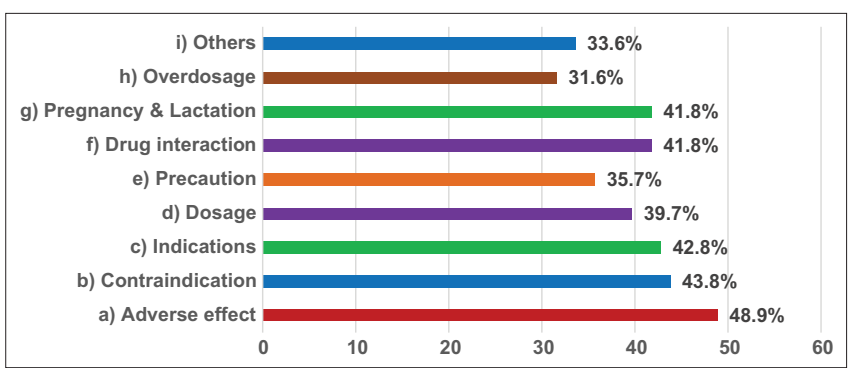

Fig. 1: Percentage of package insert columns read by students

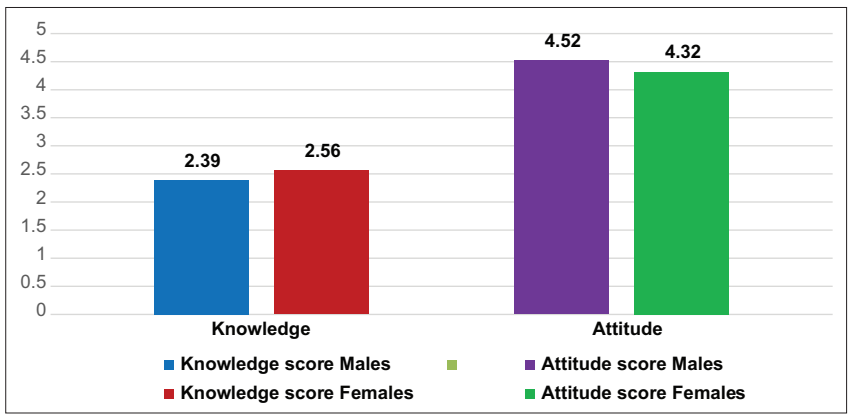

Fig. 2: Knowledge and the attitudinal score of students about package inserts

done by Gupta et al. where out of 58\% who read PI, 21\% looked for adverse effects, 195 contraindications, and 185 indications [9]. About 95.9\% ( $\mathrm{n}=94)$ said that they will refer PI in the future while prescribing as a physician. Gender-specific comparison of knowledge and attitude revealed that there was no statistically significant difference in the mean scores ( $t=0.31, p=0.76)$ of males and females. This was different from another study done by Dawoodi et al. who showed that the knowledge and awareness score of female patients about PI was more than male patients [16].

\section{Limitations}

The limitations of this study were that only 98 students were evaluated in assessing knowledge, attitude, and practice about PIs, and the study was done in a single center.

\section{CONCLUSION}

Results of this study strongly suggest that there is a need for escalating knowledge and awareness among medical students about PIs, as they are an important source of drug information for both the prescribers and patients. In developing countries like India, where the doctor/ patient ratio is much less and self-medication is more prevalent, good PIs always help to minimize the informative gap between health-care professionals and patients which, in turn, helps to reduce medication errors and improve patient compliance.

\section{ACKNOWLEDGMENT}

The authors are thankful to Dr. Dhanya and Dr. Preeja, Associate Professors in Pharmacology for helping with Protocol preparation, Statistical analysis, and Manuscript reviewing. We also acknowledge all the medical undergraduate and junior residents of the institution who participated in this study.

\section{AUTHORS' CONTRIBUTIONS}

Sneha Prabha MP - Study Idea, Protocol preparation, Data collection, Data analysis, and Manuscript preparation.

Sonish S Prabhakaran - Literature Review, Data Entry, and Analysis, Manuscript editing, review, and correspondence. (corresponding author) 


\section{CONFLICTS OF INTEREST}

No conflicts of interest to disclose.

\section{AUTHORS FUNDING}

Nil.

\section{REFERENCES}

1. Srivastava B, Prakash C, Sinha AK. Errors in drug labeling and medicolegal awareness. J Indian Acad Forensic Med 2011;32:228-30.

2. Ved JK. Package inserts in India: Need for a revision. J Int Pharm Sci Res 2010;1:454-6.

3. Food and Drug Administration, HHS. Requirements on content and format of labeling for human prescription drug and biological products. Fed Regist 2006;71:3921-97.

4. Government of India, Ministry of Health and Family Welfare, Drug and Cosmetics Rules; 1945. p. 265. Available from: http://www. emergogroup.com/sites/default/files/file/india-drugs-and-cosmeticsact-1940-act-no-23.pdf.

5. Shivalkar YM. Clinical information in drug package inserts in India. J Postgrad Med 2009;55:104-7.

6. Joubert PH, Skene D. Attitudes of private medical practitioners towards package inserts and other drug information sources. S Afr Med J 1984;66:306-7.

7. Deo M. Doctor population ratio for India-The reality. Indian J Med Res 2013;137:632-5.

8. Alhomoud FK, Alnemari W, Alfahmi H, Alhomoud F, Cheema E. Incidence and prevalence of prescribing errors in Saudi Arabia: A systematic study. Int J Pharm Pharm Sci 2016;8:194-8.

9. Gupta VK, Pathak SS. Assessment of awareness and knowledge about package inserts amongst medical students: A questionnaire-based study. IOSR J Pharm 2012;2:215-7.

10. Johnson D, Hima SS, Teena A, Kumaraswamy M, Chopra RS. Selfmedication practice among medical, pharmacy, and nursing students. Int J Pharm Pharm Sci 2016;8:443-7.

11. Dutta S, Hazarika K. Pattern of self-medication and drug use behavior among undergraduate students of medical, and non-medical colleges in a city of North-East India -a comparative study. Asian J Pharm Clin Res 2016;9:259-62.

12. Mottram DR, Reed C. Comparative evaluation of patient information leaflets by pharmacists, doctors, and the general public. J Clin Pharm Ther 1997;22:127-34.

13. Gibbs S, Waters WE, George CF. Prescription information leaflets: A national survey. J R Soc Med 1990;83:292-7.

14. Gibbs S, Waters WE, George CF. The benefits of prescription information leaflets. Br J Clin Pharmacol 1989;27:723-39.

15. European Medicines Agency. Guideline on the Packaging Information of Medicinal Products for Human Use Authorized by the Community; 2008. Available from: http://www.ec.europa.eu/enterprise/pharmaceuticals/ eudralex/vol2/c/bluebox_02 2008.pdf.

16. Dawoodi I, BhosaleU. Evaluation of knowledge and awareness of patients about prescribed drugs and their package inserts: A crosssectional study. Asian J Pharm 2016;10:S97.

17. Gupta R, Malhotra A. A study on awareness about package inserts among postgraduate medical students: An observational questionnaire based study. Int J Basic Clin Pharmacol 2019;8:1034-7.

18. Singh KR, Munshi R, Arora D. Assessment of the degree of awareness among physicians and patients about drug European medicines package inserts. Int J Pharm Sci Res 2016;7:1258-62.

19. European Medicines Agency. Guidelines on the Readability of the Labeling and Package Leaflet of Medicinal Products for Human use Revision; 2009.

20. Songara R et.al. Need for harmonization of labeling of OTC drugs. Int J Curr Pharm Res 2010;1:33-58.

21. Kafeel H. Medication package inserts, concept among doctors pharmacists and laypersons-a beneficial guidance or a source of confusion. J Med Res 2016;2:62-4.

22. Gupta VK. Vision 2015, Medical Council of India; 2011. p. 10. Available from: http://www.mciindia.org/tools/announcement/mci_booklet.

23. Al-Aqeel SA. Evaluation of medication package inserts in Saudi Arabia. Drug Healthc Patient Saf 2012;4:33-8.

24. Ahmadi P, Badri SS, Zargarzadeh AH. An investigation on patient attitudes toward package inserts and their accessibility in Iran. J Res Med Sci 2018;23:100. 